\title{
Reminiscences of Peter Wynn
}

\author{
C. Brezinski ${ }^{1}$
}

Received: 2 May 2018 / Accepted: 3 May 2018 / Published online: 10 May 2018

(C) Springer Science+Business Media, LLC, part of Springer Nature 2018

Peter Wynn passed away in December 2017 from a heart attack. He was living in Zacatecas, Mexico. I would like to recall some memories about him.

I made my military service in a scientific laboratory of the French Army in 19681969. The building next to mine was another division of the Army, the Centre de Calcul Scientifique de l'Armement, which, among other duties, had to solve numerical analysis problems for the civil and military engineers working for the Defense. When freed from my obligations in June 1969, I went to Dr. Francis Ceschino, the head of the numerical analysis group of this service, to ask him if it was possible to be employed there and, simultaneously, to work for a Doctoral Thesis, the French Thèse d'État ès Sciences Mathématiques, on a topic which agreed him and a University professor. I was hired, and Ceschino proposed me to work on convergence acceleration methods. At that time in France, there were essentially two centers for doing research in numerical analysis: the University of Paris where Jacques-Louis Lions was working on PDEs, and the University of Grenoble with Noël Gastinel who was interested by other topics. Gastinel accepted to supervise my Thesis on acceleration methods. My first work was to read the papers on Shanks' transformation and on the $\varepsilon$-algorithm of Wynn. Each paper of Wynn was citing another paper of him, I read the new paper and found another citation of him. It seemed to be an endless procedure. Thus, I decided to write a letter to Wynn (at that time the Internet was not developed) asking him to send me a complete list of his publications. He immediately answered and provided me with many reprints of his papers. This was the beginning of many epistolary exchanges. The formal tone of our first letters changed to more personal messages after some time. Peter gave me many advices; he helped me in the proofs

\section{Brezinski}

Claude.Brezinski@univ-lille.fr

1 Laboratoire Paul Painlevé, UMR CNRS 8524, UFR de Mathématiques Pures et Appliquées, Université de Lille, 59655, Villeneuve d'Ascq cedex, France 
of several of my results and discussed with me his own research. Once, he wrote to me that the only mathematicians who do not make errors are those who never publish. Without his help, my career would certainly have been different. I defended my Thesis on April 26, 1971. In 1972, he managed to have me invited to participate in the International Conference on Padé Approximation and Related Matters, in Boulder, USA, 19-22 June 1972, organized by William B. Jones and Wolfgang J. Thron. This was the first international conference I attended. There I met George Baker Jr., Michael Barnsley, Daniel Bessis, Roy Chisholm, Albert Edrei, John Gammel, Gene Golub, Bill Gragg, Yudell Luke, John Nuttall, Joe Traub, Luc Wuytack, Jean ZinnJustin, and many others with whom I stayed in contact over the years. There I also met Peter for the first time. After the congress, he invited me to give a seminar at the Centre de Recherches Mathématiques of the Université de Montréal where he was working at that time. I stayed there a few days discussing mathematics with him, and having meals in good restaurants. Our regular contacts thus continued for many years. Several of my works are a continuation of his papers and vice versa. He discussed with me the results obtained by of some of my students and colleagues. He often gave me lengthy explanations. He also took steps so that I could be invited for a long stay in Canada or the USA (but I could not take advantage of these invitations) and to get funds for my visits. I translated for him three papers he wanted to publish in French in the Comptes Rendus de l'Académie des Sciences de Paris. Once, he completely rewrote a paper of mine before its submission to a journal. We met at various occasions in Canada (for the ICM 1974), the USA, and France. In particular, he attended the Colloque d'Analyse Numérique at La Grande-Motte, France, 26 May1st June 1975, and a congress on Padé approximants in Toulon and Marseille. The last time we met was at the congress Rational Approximation with Emphasis on Padé Approximants, Tampa, USA, 15-17 December 1976, organized by Ed Saff. In 1981, Peter decided to move to Mexico. He wanted to get away, as he wrote to me, from the many futilities and stupidities of modern academic life for a year or so. But, because he was able to have a better life there, he decided to stay in the country. He first lived in Guanajuato where he was related to the Centro de Investigación en Matematicás. The cultural life of the city was very rich, and he often went to the theater and to concerts. Peter was a bon vivant enjoying good restaurants, but also a man of culture, un honnête homme in the sense of the seventeenth century with, in addition, a very British sense of humor. Although, as he wrote to me, he was working hard at mathematics and have settled many matters which previously troubled him, he did not published anything any longer. He was also planning to write one or two books, and to come to Europe giving circus performances. But these projects were not realized. However, he was still writing reviews for Zentralblatt für Mathematik und ihre Grenzgebiete. He moved to Zacatecas in 1990 and stopped to have scientific contacts as far as I know. His last paper was published in 1981, and his last letter to me dated June 1992.

Without Peter Wynn, the fields of acceleration (or extrapolation) methods, Padé approximation and continued fractions would certainly not have been so much developed, as well as their applications to fixed point methods and other topics in numerical analysis and applied mathematics I owe him a lot. Thank you Peter. 


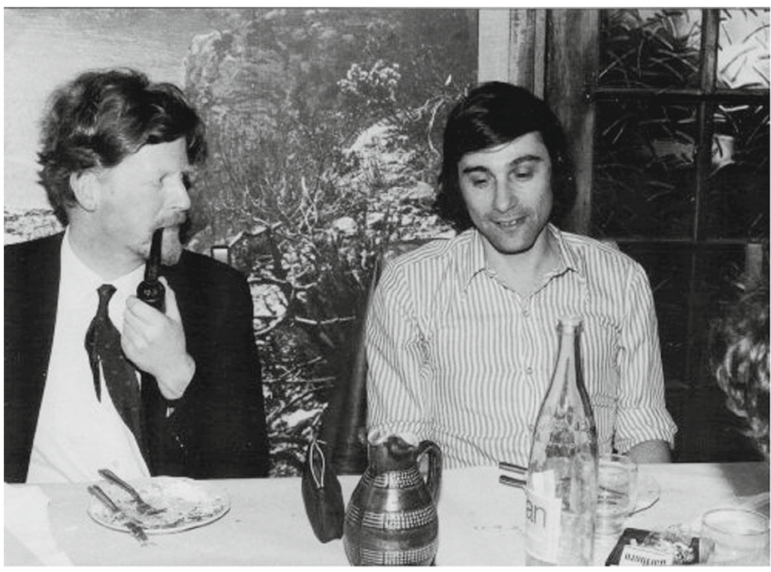

Peter Wynn with C.B. in 1975

\section{References}

1. Wynn, P.: A note on Salzer's method for summing certain convergent series. J. Math. Phys. 35, 318-320 (1956)

2. Wynn, P.: On a procrustean technique for the numerical transformation of slowly convergent sequences and series. Math. Proc. Camb. Philos. Soc. 52, 663-671 (1956)

3. Wynn, P.: On a device for computing the $e_{m}\left(s_{n}\right)$ transformation. Math. Tables Aids Comput. 10, 91-96 (1956)

4. Wynn, P.: On a cubically convergent process for determining the zeros of certain functions. Math. Tables Aids Comput. 10, 97-100 (1956)

5. Wynn, P.: Central difference and other forms of the Euler transformation. Quart. J. Mech. Appl. Math. 9, 249-256 (1956)

6. Wynn, P.: On the propagation of error in certain non-linear algorithms. Numer. Math. 1, 142-149 (1959)

7. Wynn, P.: A sufficient condition for the instability of the q-d algorithm. Numer. Math. 1, 203-207 (1959)

8. Wynn, P.: Converging factors for continued fractions. Numer. Math. 1, 272-307; 308-320 (1959)

9. Wynn, P.: ÜBer einen Interpolations-algorithmus und gewisse andere Formeln, die in der Theorie der Interpolation durch rationale Funktionen bestehen. Numer. Math. 2, 151-182 (1960)

10. Wynn, P.: The rational approximation of functions which are formally defined by a power series expansion. Math. Comput. 14, 147-186 (1960)

11. Wynn, P.: Confluent forms of certain non-linear algorithms. Arch. Math. 11, 233-236 (1960)

12. Wynn, P.: A note on a confluent form of the $\varepsilon$-algorithm. Arch. Math. 11, 237-240 (1960)

13. Wynn, P.: A comparison between the numerical performances of the Euler transformation and the $\varepsilon$-algorithm. Revue Française de Traitement de l'information Chiffres 1, 23-29 (1961)

14. Wynn, P.: On the tabulation of indefinite integrals. BIT 1, 286-290 (1961)

15. Wynn, P.: L' $\varepsilon$-algorithmo e la tavola di Padé. Rend. Mat. Roma. 20, 403-408 (1961)

16. Wynn, P.: The epsilon algorithm and operational formulas of numerical analysis. Math. Comput. 15, $151-158$ (1961)

17. Wynn, P.: On repeated application of the epsilon algorithm. Revue Française de Traitement de l'information Chiffres 4, 19-22 (1961)

18. Wynn, P.: The numerical transformation of slowly convergent series by methods of comparison. Revue Française de Traitement de l'information Chiffres 4, 177-210 (1961)

19. Wynn, P.: A sufficient condition for the instability of the $\varepsilon$-algorithm. Nieuw Arch. Wiskd. 9, 117119 (1961) 
20. Wynn, P.: A note on a method of Bradshaw for transforming slowly convergent series and continued fractions. Amer. Math. Monthly 69, 883-889 (1962)

21. Wynn, P.: Upon a second confluent form the $\varepsilon$-algorithm. Proc. Glasgow Math. Assoc. 5, 160-165 (1962)

22. Wynn, P.: Acceleration techniques for iterated vector and matrix problems. Math. Comput. 16, 301322 (1962)

23. Wynn, P.: A comparison technique for the numerical transformation of slowly convergent series based on the use of rational functions. Numer. Math. 4, 8-14 (1962)

24. Wynn, P.: Numerical efficiency profile functions. Koninkl. Nederl. Akad. Wet. 65A, 118-126 (1962)

25. Wynn, P.: The numerical efficiency of certain continued fraction expansions. Koninkl. Nederl. Akad. Wet. 65A, 127-148 (1962)

26. Wynn, P.: On a connection between two techniques for the numerical transformation of slowly convergent series. Koninkl. Nederl. Akad. Wet. 65A, 149-154 (1962)

27. Wynn, P.: Una nota su un analogo infinitesimale del q-d algoritmo. Rend. Mat. Roma 21, 77-85 (1962)

28. Wynn, P.: A note on fitting certain types of experimental data. Stat. Neerl. 16, 145-150 (1962)

29. Wynn, P.: Note on the solution of a certain boundary-value problem. BIT 2, 61-64 (1962)

30. Wynn, P.: An arsenal of ALGOL procedures for complex arithmetic. BIT 2, 232-255 (1962)

31. Wynn, P.: The numerical transformation of slowly convergent series by methods of comparison. II. Revue Française de Traitement de l'information Chiffres 5, 65-88 (1962)

32. Wynn, P.: Acceleration technique in numerical analysis with particular reference to problems in one independent variable. In: Popplewell, C.M. (ed.) Information Processing 1962, Proceedings of IFIP Congress 62, Munich, 27 August - 1st September 1962, pp. 149-156. North-Holland, Amsterdam (1963)

33. Wynn, P.: Singular rules for certain non-linear algorithms. BIT 3, 175-195 (1963)

34. Wynn, P.: Note on a converging factor for a certain continued fraction. Numer. Math. 5, 332-352 (1963)

35. Wynn, P.: On a connection between the first and the second confluent form of the $\varepsilon$-algorithm. Niew. Arch. Wisk. 11, 19-21 (1963)

36. Wynn, P.: Continued fractions whose coefficients obey a non-commutative law of multiplication. Arch. Ration. Mech. Anal. 12, 273-312 (1963)

37. Wynn, P.: A numerical study of a result of Stieltjes. Revue Française de Traitement de l'information Chiffres 6, 175-186 (1963)

38. Wynn, P.: Converging factors for the Weber parabolic cylinder function of complex argument. Proc. Kon. Nederl. Akad. Weten. 66, 721-754 (1963)

39. Wynn, P.: Partial differential equations associated with certain non-linear algorithms. Z. Angew. Math. Phys. 15, 273-289 (1964)

40. Wynn, P.: General purpose vector epsilon-algorithm Algol procedures. Numer. Math. 6, 22-36 (1964)

41. Wynn, P.: On some recent developments in the theory and application of continued fractions. SIAM J. Numer. Anal., Ser. B. 1, 177-197 (1964)

42. Wynn, P.: Four lectures on the numerical application of continued fractions. In: Ghizzetti, A. (ed.) Alcune Questioni di Analisi Numerica. Series: C.I.M.E. Summer Schools, vol. 35, pp. 111-251. Springer, Heidelberg (1965)

43. Wynn, P.: A note on programming repeated application of the epsilon-algorithm. Revue Française de Traitement de l'information Chiffres 8, 23-62 (1965)

44. Wynn, P.: Upon systems of recursions which obtain among the quotients of the Padé table. Numer. Math. 8, 264-269 (1966)

45. Wynn, P.: On the convergence and stability of the epsilon algorithm. SIAM J. Numer. Anal. 3, 91-122 (1966)

46. Wynn, P.: Upon a Conjecture Concerning a Method for Solving Linear Equations, and Certain Other Matters, MRC Technical Summary Report 626, University of Wisconsin, Madison (1966)

47. Wynn, P.: Complex Numbers and Other Extensions to the Clifford Algebra with an Application to the Theory of Continued Fractions, MRC Technical Summary Report 646, University of Wisconsin, Madison (1966)

48. Wynn, P.: Upon the Diagonal Sequences of the Padé Table, MRC Technical Summary Report 660, University of Wisconsin, Madison (1966) 
49. Wynn, P.: Accelerating the Convergence of a Monotonic Sequence by a Method of Intercalation, MRC Technical Summary Report 674, University of Wisconsin, Madison (1966)

50. Wynn, P.: Upon an Invariant Associated with the Epsilon Algorithm, MRC Technical Summary Report 675, University of Wisconsin, Madison (1966)

51. Wynn, P.: On the computation of certain functions of large argument and parameter. BIT 6, 228-259 (1966)

52. Wynn, P.: An arsenal of Algol procedures for the evaluation of continued fractions and for effecting the epsilon algorithm. Revue Française de Traitement de l'information Chiffres 9, 327-362 (1966)

53. Wynn, P.: A general system of orthogonal polynomials. Quart. J. Math. Oxford (2) 18, 81-96 (1967)

54. Wynn, P.: Transformations to accelerate the convergence of Fourier series. In: Mond, B., Blanch, G. (eds.) Gertrude Blanch Anniversary Volume, pp. 339-379. Wright Patterson Air Force Base (1967)

55. Wynn, P.: A Note on the Convergence of Certain Noncommutative Continued Fractions, MRC Technical Summary Report 750, University of Wisconsin, Madison (1967)

56. Wynn, P.: Upon the Padé table derived from a Stieltjes series. SIAM J. Numer. Anal. 5, 805-834 (1968)

57. Wynn, P.: Vector continued fractions. Linear Algebra Appl. 1, 357-395 (1968)

58. Wynn, P.: Upon the definition of an integral as the limit of a continued fraction. Arch. Ration. Mech. Anal. 28, 83-148 (1968)

59. Wynn, P.: Zur Theorie der mit gewissen speziellen Funktionen verknüpften Padéschen Tafeln. Math. Z. 109, 66-70 (1969)

60. Wynn, P.: Upon a Recursive System of Flexible Rings Permitting Involution, Report CRM-50, Centre De Recherches Mathématiques, Université de Montréal, Montréal (1970)

61. Wynn, P.: Upon the Inverse of Formal Power Series over Certain Algebra, Report CRM-53, Centre De Recherches Mathématiques, Université de Montréal, Montréal (1970)

62. Wynn, P.: Upon a Hierarchy of Epsilon Arrays, Technical Report 46, Louisiana State University, New Orleans (1970)

63. Wynn, P.: A note on the generalised Euler transformation. Comput. J. 14, 437-441 (1971). Errata 15, 175 (1972)

64. Wynn, P.: The Abstract Theory of the Epsilon Algorithm, Report CRM-74, Centre De Recherches Mathématiques, Université de Montréal, Montréal (1971)

65. Wynn, P.: A Note upon Totally Monotone Sequences, Report CRM-139, Centre De Recherches Mathématiques, Université de Montréal, Montréal (1971)

66. Wynn, P.: A transformation of series. Calcolo 8, 255-272 (1971)

67. Wynn, P.: Difference-differential recursions for Padé quotients. Proc. London Math. Soc., S. 3 23, 283-300 (1971)

68. Wynn, P.: Upon the generalized inverse of a formal power series with vector valued coefficients. Compo. Math. 23, 453-460 (1971)

69. Wynn, P.: ÜBer orthogonale Polynome und ein assoziiertes Momentproblem. Math. Scand. 29, 104112 (1971)

70. Wynn, P.: On an extension of a result due to Pólya. J. Reine Angew. Math. 248, 127-132 (1971)

71. Wynn, P.: Convergence acceleration by a method of intercalation. Computing 9, 267-273 (1972)

72. Wynn, P.: Invariants associated with the epsilon algorithm and its first confluent form. Rend. Circ. Mat. Palermo. 21, 31-41 (1972)

73. Wynn, P.: Hierarchies of arrays and function sequences associated with the epsilon algorithm and its first confluent form. Rend. Mat. Roma, 5, Serie VI, 819-852 (1972)

74. Wynn, P.: A Note on a Partial Differential Equation, Report CRM-22, Centre De Recherches Mathématiques, Université de Montréal, Montréal (1972)

75. Wynn, P.: Sur les suites totalement monotones. C.R. Acad. Sci. Paris 275A, 1065-1068 (1972)

76. Wynn, P.: Transformation de séries à l'aide de l' $\varepsilon$-algorithm. C.R. Acad. Sci. Paris 275A, 1351-1353 (1972)

77. Wynn, P.: Upon a convergence result in the theory of the Padé table. Trans. Amer. Math. Soc. 165, 239-249 (1972)

78. Wynn, P.: A Convergence Theory of Some Methods of Integration, Report CRM-193, Centre De Recherches Mathématiques, Université de Montréal, Montréal (1972)

79. Wynn, P.: The Partial Differential Equation of the Padé Surface, Report CRM-197, Centre De Recherches Mathématiques, Université de Montréal, Montréal (1972) 
80. Wynn, P.: The Algebra of Certain Formal Power Series, Report CRM-216, Centre De Recherches Mathématiques, Université de Montréal, Montréal (1972)

81. Wynn, P.: Upon some continuous prediction algorithms. I. Calcolo 9, 197-234 (1973)

82. Wynn, P.: Upon some continuous prediction algorithms. II. Calcolo 9, 235-278 (1973)

83. Wynn, P.: On Some Extensions of Euclid's Algorithm, and Some Consequences Thereof, Report CRM, Centre de Recherches Mathématiques, Université de Montréal, Montréal (1972)

84. Wynn, P.: Distributing Rings Permitting Involution, Report CRM-281, Centre De Recherches Mathématiques, Université de Montréal, Montréal (1973)

85. Wynn, P.: On the zeros of certain confluent hypergeometric functions. Proc. Amer. Math. Soc. 40, 173-183 (1973)

86. Wynn, P.: Accélération de la convergence de séries d'opérateurs en analyse numérique. C.R. Acad. Sci. Paris 276A, 803-806 (1973)

87. Wynn, P.: On the intersection of two classes of functions. Rev. Roumaine Math. Pures Appl. 19, 949-959 (1974)

88. Wynn, P.: Extremal properties of Padé quotients. Acta Math. Hungar. 25, 291-298 (1974)

89. Wynn, P.: Sur l'équation aux dérivées partielles de la surface de Padé. C.R. Acad. Sci. Paris 278A, 847-850 (1974)

90. Wynn, P.: A Numerical Method for Estimating Parameters in Mathematical Models, Report CRM443, Centre de Recherches Mathématiques, Université de Montréal, Montréal (1974)

91. Wynn, P.: Some recent developments in the theories of continued fractions and the Padé table. Rocky Mountain J. Math. 4, 297-324 (1974)

92. Wynn, P.: How to integrate without integrating, Colloque Euromech 58, Toulon, 1975, unpublished

93. Wynn, P.: A class of functions connected with the approximate solution of operator equations, Workshop on Padé approximants, Marseille, 1975, unpublished

94. Wynn, P.: Upon a class of functions connected with the approximate solution of operator equations. Ann. Mat. Pura Appl. 104, 1-29 (1975)

95. Wynn, P.: Five lectures on the numerical application of continued fractions, Orientation Lecture Series 5, MRC, University of Wisconsin, Madison

96. Wynn, P.: The algebra of certain formal power series. Riv. Mat. Uni. Parma 2, 155-176 (1976)

97. Wynn, P.: An Array of Functions, Report, School of Computer Science, McGill University, Montreal (1976)

98. Wynn, P.: A Continued Fraction Transformation of the Euler-MacLaurin Series, Report, School of Computer Science, McGill University, Montreal (1976)

99. Wynn, P.: The Evaluation of Singular and Highly Oscillatory Integrals by Use of the Antiderivative, Report, School of Computer Science, McGill University, Montreal (1976)

100. Wynn, P.: A convergence theory of some methods of integration. J. Reine Angew. Math. 285, 181208 (1976)

101. Wynn, P.: The calculus of finite differences over certain systems of numbers. Calcolo 14, 303-341 (1977)

102. Wynn, P.: The transformation of series by the use of Padé quotients and more general approximants. In: Saff, E.B., Varga, R.S. (eds.) Padé and Rational Approximation. Theory and Applications, pp. 121-144. Academic Press, New York (1977)

103. Wynn, P.: The convergence of approximating fractions. Bol. Soc. Mat. Mexicana 26, 57-71 (1981)

104. Wynn, P.: The work of E.B. Christoffel on the theory of continued fractions. In: Butzer, P.L., Fehér, F. (eds.) E.B. Christoffel: the Influence of His Work on Mathematics and the Physical Sciences, pp. 190-202. Birkhäuser, Basel (1981)

105. Wynn, P.: Remark upon developments in the theories of the moment problem and of quadrature, subsequent to the work of Christoffel. In: Butzer, P.L., Fehér, F. (eds.) E.B. Christoffel: the Influence of His Work on Mathematics and the Physical Sciences, pp. 731-734. Birkhäuser, Basel (1981)

\section{Translations}

106. Khintchine, A.Y.: Continued Fractions, Translated from Russian by Peter Wynn, P. Noordhoff N.V., Groningen (1963)

107. Khovanskii, A.N.: The Application of Continued Fractions and Their Generalizations to Problems in Approximation Theory. Translated from Russian by Peter Wynn, P. Noordhoff N.V., Groningen (1963) 